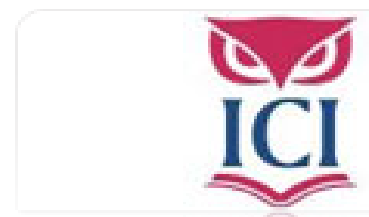

IUS. Revista del Instituto de Ciencias Jurídicas de Puebla A.C.

ISSN: $1870-2147$

revista.ius@hotmail.com

Instituto de Ciencias Jurídicas de Puebla A. C.

México

Gómez Taboada, Jesús

El derecho de familia en España: breves comentarios sobre problemas muy particulares IUS. Revista del Instituto de Ciencias Jurídicas de Puebla A.C., núm. 20, 2007, pp. 66-77 Instituto de Ciencias Jurídicas de Puebla A. C.

Puebla, México 


\title{
EL DERECHO DE FAMILIA EN ESPAÑA: BREVES COMENTARIOS SOBRE PROBLEMAS MUY PARTICULARES
}

\author{
Jesús Gómez Taboada*
}

SUMARIO

I. Algunas innovaciones recientes: los matrimonios entre homoseXuales Y LAS UNIONES DE HECHO (HOMOSEXUALES Y HETEROSEXUALES) I.I UBiCACIÓN: EL CONTEXTO POLITICO: ARgUMENTOS A FAVOR, ARGUMENTOS EN CONTRA II. Efectos revocatorios de la Separación de hecho de los cónyuges II.I. LA REVOCACIÓN DEL PODER

\section{RESUMEN}

El artículo analiza el cambio introducido en el ordenamiento español por el cual se legitima el matrimonio entre parejas de un mismo sexo, postura avanzada sostenida por el Partido Socialista Obrero Español a diferencia de la que esgrimía el Partido Popular que había barajado durante su gobierno de opción de uniones civiles. Los argumentos que sustentaron la nueva ley se apoyan sobre todo en la libertad y en la igualdad, ambos valores superiores del ordenamiento jurídico español. Esta tesis no consideró un escollo: el artículo 32 de la Constitución cuyo párrafo primero señala que "El hombre y la mujer tienen derecho a contraer matrimonio con plena igualdad jurídica", reinterpretándose no como que da cobertura sólo a la unión hombre-mujer, sino a la unión del hombre y la mujer. El autor expone

\section{ABSTRACT}

The article analyzes the change introduced in the Spanish classification by which the marriage is legitimated among even of oneself sex, advanced posture sustained by the PSOE contrary to which the pp that had shuffled during its government of option of civil unions fenced. The arguments that sustained the new law lean on mainly in the Freedom and in the Equality, both superior securities of the Spanish juridical classification. This thesis didn't consider a reef the article 32 of the Constitution that he/she writes that "The man and the woman are entitled to get married with full artificial equality", looking at you doesn't eat that he/she gives alone covering to the union man-woman, but to the union of men and the women. The author exposes the ideas that have

* Notario de Tordera, Barcelona, España. 
las ideas que se han manejado en contra been managed against such a posture, de tal postura, señalando que la mayo- pointing out that most of they are emoria de ellas son emocionales y que la más tional and that the most rational can be racional puede estar a partir de uno de starting from one of the objectives of los objetivos del matrimonio que es el de the marriage that is the one of procreprocrear, cuestión que no pueden lograr ating, question that the couples cannot las parejas de un mismo sexo. achieve of oneself sex.

\section{Algunas innovaciones ReCientes: Los matrimonios entre homosexuales Y LAS UNIONES DE HECHO (HOMOSEXUALES Y HETEROSEXUALES)}

\section{I.I. UBICACIÓN: EL CONTEXTO POLÍTICO: ARGUMENTOS A FAVOR, ARGUMENTOS EN CONTRA}

La ley ha aprobado, como su propio nombre indica, una importante reforma en el derecho de familia español, consistente en la extensión del matrimonio civil a personas del mismo sexo, ${ }^{1}$ convirtiéndose así España en uno de los pocos países del mundo en permitir este vínculo.

La ley fue impulsada por el Partido Socialista Obrero Español (izquierda), en el gobierno desde las elecciones generales de 14 de marzo de $2004 .{ }^{2}$ Y fue apoyada por todos los grupos parlamentarios del Congreso español, con el voto en contra del Partido Popular (derecha). ${ }^{3}$

En la legislatura anterior (2000-2004) el Partido Popular había barajado la posibilidad de promulgar una "ley de uniones civiles" que diera cabida

\footnotetext{
' Sin entrar en mayores detalles, y menos en polémicas, diremos que la ley no va dirigida, necesariamente, a personas homosexuales, sino a las del mismo sexo, sean o no homosexuales. Es decir, podrán contraer matrimonio dos personas del mismo sexo sin obligación de acreditar su calidad de homosexuales.

${ }^{2}$ En España hay cuatro elecciones diferentes, todas ellas con una cadencia de cuatro años: las generales, que determinan la distribución de las cámaras estatales, Congreso de los Diputados y Senado (esta última, irrelevante y siempre pendiente de una reforma, poco aclarada, que la convierta en un Parlamento de representación territorial. En definitiva: lo importante es ganar en el Congreso). Las autonómicas, que eligen a los representantes de los parlamentos de las diecisiete comunidades autónomas (más las ciudades autónomas norteafricanas de Ceuta y Melilla) en que se distribuye, territorialmente, el Estado español. Las municipales, que deciden la composición de los ayuntamientos. Y las europeas, que determinan la representación española en el Parlamento Europeo de Estrasburgo (organismo de la Unión Europea).

${ }^{3}$ El PSOE obtuvo, en estas elecciones, 164 diputados; y el Partido Popular, hasta entonces en el gobierno, 148. Dado que el Congreso de los Diputados tiene un total de 350 miembros, la mayoría absoluta está situada en 176. El partido socialista gobierna, por tanto, en minoría, si bien con el apoyo parlamentario de los ocho diputados de Esquerra Republicana de Cataluña (partido independentista catalán) y de los cuatro de lzquierda Unida-Iniciativa por Cataluña-Los Verdes (conglomerado formado por comunistas y ecologistas).
} 
a las parejas de hecho heterosexuales y homosexuales. ${ }^{4}$ La idea no pasó de anteproyecto de ley y quedó pendiente para la siguiente legislatura (la actualmente vigente: 2004-2008). Pero la pérdida de las elecciones por parte de este partido, que gobernaba hasta 2004 con una holgada mayoría absoluta (183 diputados) aparcó esa opción. Y el partido socialista, una vez en el poder, logró sacar adelante su promesa electoral de modificar el Código Civil para extender el matrimonio a personas del mismo sexo.

\section{Argumentos a favor}

Los argumentos que se han esgrimido a favor de la nueva ley se apoyan, sobre todo, en la libertad y en la igualdad, ambos "valores superiores de nuestro Ordenamiento Jurídico", ${ }^{5}$ a tenor del artículo primero de la Constitución española de 1978. Libertad para "elegir la opción sexual" que cada cual crea conveniente. E igualdad para equiparar los derechos de las parejas homosexuales a las heterosexuales. La igualdad está desarrollada, en la propia Constitución, en el artículo 14.

No hay razón, por tanto, según los defensores de esta ley, para restringir el matrimonio a parejas de diferente sexo y negar a los que son del mismo sexo los mismos derechos.

¿Por qué, por ejemplo, debe existir una pensión compensatoria, como la reconocida en el artículo 97 del Código Civil ${ }^{6}$ para las parejas heterosexuales y no para las homosexuales? El daño sufrido por la parte perjudicada es, en condiciones idénticas, el mismo. Este argumento está en íntima relación con el del enriquecimiento injusto: es decir, el beneficio que una de las partes pueda haber obtenido como consecuencia de la convivencia y que se considere como causa de indemnización si el otro ha sufrido un perjuicio correlativo. ${ }^{7}$

${ }^{4}$ Aunque no lo podemos saber, es posible que la aprobación de esa ley hubiera evitado, o complicado al menos, la aprobación de la de 2005. En cualquier caso, sigue siendo muy conveniente, por no decir indispensable, la armonización del régimen jurídico de las parejas de hecho, heterosexuales y homosexuales, perdidas, en la actualidad, en un mosaico de legislaciones autonómicas que provocan, sobre todo, inseguridad jurídica. Ello, siempre y cuando se considere -como lo consideran los legisladores autonómicos de nuestro país- adecuado el regular estas uniones de hecho.

${ }_{5}^{5}$ Para un análisis más extenso, ver Gregorio, Peces-Barba, "Los valores superiores", en la colección Temas clave de la Constitución española, Tecnos, Madrid, 1983.

6 "El cónyuge al que la separación o divorcio produzca desequilibrio económico en relación con la posición del otro que implique un empeoramiento en su situación anterior en el matrimonio, tiene derecho a una pensión..."

${ }^{7}$ De hecho, el propio artículo 97 incluye (número $5^{\circ}$ ), entre los elementos que deben tomarse en cuenta para determinar la pensión compensatoria, "la colaboración en las actividades mercantiles, industriales 
Esta tesis no considera un escollo el artículo 32 de la propia Constitución, cuyo párrafo primero señala que: "El hombre y la mujer tienen derecho a contraer matrimonio con plena igualdad jurídica." ${ }^{8}$ Es decir, no consideran que ello implique que el hombre, si se casa, deba hacerlo, necesariamente, con una mujer; y viceversa. Sino que también pueden casarse entre sí los hombres y las mujeres.

\section{Argumentos en contra}

En contra de la nueva regulación se invoca, sobre todo, la idea de que el matrimonio siempre ha sido una institución que ha unido a hombre y mujer, nunca a dos personas del mismo sexo.

Hay autores que consideran que la unión matrimonial de hombre y mujer es de derecho natural; en virtud del mismo, "la unión fecunda de los dos sexos debe convenirse libremente entre un hombre y una mujer con la voluntad de cumplir el fin natural de su unión de manera permanente y sin participación de otras personas en tal intimidad sexual", ${ }^{9}$ de manera que "las uniones homosexuales no son matrimonio, y sólo últimamente se intenta olvidar esta certeza". ${ }^{10}$

Estas tesis se apoyan, también, en la consideración del matrimonio como instituto dirigido a la procreación. Y, por naturaleza, este efecto no se puede conseguir con uniones homosexuales.

El Partido Popular, que, como antes dijimos, votó en contra de la ley, estaba dispuesto a mantener su contenido siempre que no se le llamase a esa unión "matrimonio", palabra que hace referencia a la madre (de matri-

o profesionales del otro cónyuge".

${ }^{8}$ Este artículo está encuadrado dentro del capítulo dedicado a los "derechos de los ciudadanos" (artículos 29 a 38 de la propia Constitución), grupo formado por una serie de derechos (propiedad, herencia, sindicación...) de categoría inferior a los que se incluyen entre "los derechos fundamentales y las libertades públicas” (artículos 14 a 28: reunión, asociación, libertad religiosa...). La diferencia radica, como es lógico, en su régimen jurídico, muy en especial en lo relativo a su protección (recordemos: el derecho son efectos; y, todo lo demás, literatura). En concreto: a) los "derechos fundamentales" y las "libertades públicas" tienen que ser reguladas por Ley Orgánica (artículo 81 de la Constitución española) que requiere la aprobación, por mayoría absoluta, del Congreso -ya vimos que es la Cámara que cuenta-, y tienen un mecanismo de protección excepcional: el recurso de amparo ante el Tribunal Constitucional (artículo 53.1 de la Constitución española); b) los "derechos de los ciudadanos" gozan de reserva de ley, pero esta ley es ordinaria, susceptible, por tanto, de ser aprobada por mayoría simple, y no cuentan, además, con la protección citada del recurso de amparo (un estudio, desde la doble perspectiva procesal y constitucional, de esta vía ante el Tribunal Constitucional lo encontramos en Gimeno Sendra y Cascajo Castro, "El recurso de amparo", en la colección Temas clave de la Constitución española, Tecnos, Madrid 1983

${ }^{9}$ Vid. d’Ors, Alvaro, Derecho y sentido común, Cuadernos Civitas, Madrid, 1999.

${ }^{10}$ Vid. d'Ors, Álvaro, Nueva introducción al estudio del derecho, Cuadernos Civitas, Madrid 1999. 
monium, oficio - munus - de la madre; en contraposición al patrimonium, oficio del padre, consistente en la gestión personal de los bienes). Es decir, este partido político estaba dispuesto a mantener los efectos de la unión entre dos hombres, o dos mujeres, previsto por la ley aprobada, pero sin la denominación de matrimonio.

Al final, como sabemos, la ley se aprobó, si bien ha sido recurrida, por el propio Partido Popular, ante el Tribunal Constitucional, ${ }^{11}$ por considerar que vulnera el espíritu y la letra del citado artículo 32 de nuestra ley fundamental.

El problema, en mi opinión, no radica en el nombre que se le dé a la figura jurídica que vincule a dos hombres o dos mujeres con los mismos efectos del matrimonio. Al fin y al cabo, el derecho son efectos. Por lo que no me parece razonable atribuir a dos figuras jurídicas los mismos efectos $y$, sin embargo, llamarlas de manera diferente.

El asunto debemos llevarlo, pues, a otro terreno. ${ }^{12}$ Precisamente el de los efectos, el de las consecuencias. Como sabemos, las normas jurídicas se caracterizan, a diferencia de otras (como las morales, o las de cortesía social, por ejemplo) por su exigibilidad coactiva, ejerciéndose esta coacción por los órganos del Estado. ${ }^{13}$ En el tema que nos ocupa, la coerción consiste en atribuir a las partes el cumplimiento forzoso de los deberes de la otra parte: sobre todo, pensiones periódicas o compensaciones para el caso de separación o divorcio. El perjudicado por el incumplimiento de la

${ }^{11}$ El Tribunal Constitucional, que no forma parte del poder judicial, es, según la propia Constitución, el máximo intérprete de la misma. Además del recurso de amparo a que antes hicimos referencia, le corresponde determinar la adecuación a la Constitución de las leyes que se sometan a esta calificación por las personas y órganos que están legitimados para ello. La interposición del recurso no suspende la aplicación de la norma impugnada -aspecto, como podemos intuir, no menor; además, no siempre ha sido así-. También le compete, por último, resolver los llamados conflictos de competencia, planteados entre el Estado central y las comunidades autónomas (las leyes de uno y otras no se rigen por el principio de jerarquía - como el que media entre una ley y un decreto-, sino por el de competencia, estando dibujado el cuadro general en los artículos 148 y 149 de la propia Constitución).

${ }^{12}$ En el razonamiento que a continuación planteo, he tenido muy en cuenta el trabajo, inédito, de Eduardo Cid Sánchez, "El matrimonio homosexual: su fundamento", al cual he tenido acceso por deferencia del autor.

${ }^{13}$ La coactividad o coercibilidad no es exclusiva de las normas jurídicas. Otras, como las derivadas de negocios no amparados por el derecho o de usos sociales también tienen su coacción; en ocasiones más fuerte, incluso, que las de las normas jurídicas. Pensemos, por ejemplo, en las deudas derivadas del juego prohibido: el derecho español no reconoce la exigibilidad (jurídica) de las mismas; en efecto, el artículo 1798 nos dice en su inciso primero que "La ley no concede acción para reclamar lo que se gana en un juego de suerte, envite o azar..." Sin embargo, la sanción social que el jugador moroso sufre puede llegar a ser mucho peor que la derivada de su exigibilidad jurídica. Y el incumplimiento de algunas normas sociales también puede ser muy perjudicial para el transgresor; por ejemplo, "no asistir a un funeral, al que se está obligado por la relación con el difunto o con la familia de éste es imperdonable" (Ángel Amable, Las buenas maneras, Barcelona, 1988). 
otra parte, puede acudir al juez para que éste obligue al cumplimiento. ${ }^{14}$ El quid de la cuestión es: ¿cuál es el bien jurídico que se protege? Es decir, ¿por qué se atribuye esta facultad de exigir al perjudicado?

En el caso de los matrimonios hasta ahora regulados, los heterosexuales, parece que esa obligatoriedad radica, sobre todo, en los hijos. El hombre, cuando nace, requiere una serie de cuidados, bastante intensos y muy duraderos (varios años), proporcionados, en principio, por sus padres. La defensa de la perdurabilidad del matrimonio parece radicar ahí: en la protección de los hijos, incapaces, como decimos, de valerse por sí mismos, hasta que alcancen cierta edad... Es decir: la protección del matrimonio, su cobertura jurídica, no parece radicar en la idea de un compromiso, un contrato entre los cónyuges. No. Muy al contrario: se considera un bien jurídico protegido en cuanto ayuda a la perdurabilidad de la especie.

Esta consideración no es aplicable, como bien sabemos, a las parejas homosexuales. Dos mujeres o dos hombres no pueden entre sí tener hijos de manera natural. Por lo que, si le atribuimos cobertura jurídica a la unión entre ambos (matrimonio), el bien jurídico protegido no es ya la perpetuación de la especie, la protección de los hijos. Es, por fuerza, otra cosa. ¿Cuál? El vínculo creado entre ellos, de manera voluntaria. Y que, de la misma manera voluntaria, por la sola la decisión unilateral de uno de ellos puede deshacerse. ${ }^{15}$ Nos movemos en el campo de las emociones.

Si se considera esa sola voluntad, con facultad de desistimiento, como suficiente para proteger el vínculo, la admisión del matrimonio entre personas del mismo sexo es adecuada. $\mathrm{Si}$, al contrario, se entiende que la regulación del matrimonio - la búsqueda de su perdurabilidad- tiene su razón última en la protección de los hijos, de la especie en general, este matrimonio no debe protegerse, no debe regularse, pues se apoya, como hemos visto, en otra cosa.

La no regulación de estos matrimonios dejaría huérfano un problema antes apuntado, el del enriquecimiento injusto. De hecho, este argumento ha sido uno de los más utilizados para defender la regulación de las

\footnotetext{
${ }^{14}$ Así, el artículo 90 del Código Civil, relativo a los convenios reguladores entre los cónyuges en casos de crisis matrimonial, nos dice (párrafo segundo in fine) que "desde su aprobación judicial podrán hacerse efectivos por la vía de apremio".

${ }^{15}$ Aunque el matrimonio es un negocio jurídico bilateral, se diferencia del contrato en la posibilidad de desistimiento por una de las partes; pues la regla general en éste, en el contrato, es otra, la recogida, en nuestro derecho, en el artículo 1256 del Código Civil: "La validez y el cumplimiento de los contratos no puede dejarse al arbitrio de uno de los contratantes.”
} 
uniones estables de pareja (heterosexuales y homosexuales). ${ }^{16}$ También es discutible, pues el ordenamiento jurídico ya dispone de una serie de mecanismos que corrigen ese desplazamiento patrimonial no justificado.

\section{Efectos Revocatorios de la Separación de heCho de los cónyuges}

\section{II.I. LA REVOCACIÓN DEL PODER}

Me propongo ahora referirme a uno de los efectos que se producen cuando los cónyuges se separan de hecho: la extinción de los poderes que se hubiesen atribuido.

Punto de partida: causas generales de extinción del apoderamiento

El artículo 1732 del Código Civil, que abre el capítulo dedicado a "Los modos de acabarse el mandato", ${ }^{17}$ dice:

El mandato se acaba:

1. Por su revocación.

2. Por la renuncia o incapacitación del mandatario.

3. Por la muerte, declaración de prodigalidad o por concurso o insolvencia del mandante o del mandatario.

El mandato se extinguirá, también, por la incapacitación sobrevenida del mandante a no ser que en el mismo se hubiera dispuesto su continuación o el mandato se hubiera dado para el caso de incapacidad del mandante apreciada conforme a lo dispuesto por éste. En estos casos, el mandato podrá terminar por resolución judicial dictada al constituirse el organismo tutelar o posteriormente a instancia del tutor.

\footnotetext{
${ }^{16}$ La regulación de las uniones de hecho es materia bastante compleja. Ya adelantábamos antes que en España hay una creciente "legorrea" en esta materia, traducida en leyes tendentes a igualar los efectos de estas uniones con el del matrimonio; y llegándose, incluso, a imponer esa regulación aunque no haya sido deseada por la pareja de común acuerdo. El Código Civil todavía dice (artículo 45.1) que "no hay matrimonio sin consentimiento matrimonial", aserto que hoy tenemos que poner en tela de juicio a la vista de algunas leyes de parejas estables no casadas, cuya aplicación se produce ex lege (vid. artículo 2 de la ley de 15 de julio de 1998 del Parlamento Catalán).

${ }^{17}$ En el derecho español la representación no viene regulada de manera autónoma y sistemática. Su régimen se da por supuesto y, por esa razón, aparece mencionada en múltiples preceptos. No obstante, sí hay una regulación específica y bastante completa del contrato de mandato, recogida en los artículos 1709 a 1739 del Código Civil. Aunque el mandato es un contrato bilateral y el apoderamiento un negocio jurídico unilateral, jurisprudencia y doctrina no han dudado en aplicar la normativa del primero al apoderamiento. Éste, no obstante, puede existir sin mandato; e incluso apoyarse en otra relación jurídica distinta, como el contrato de trabajo o el de sociedad (respecto a este último, el artículo 1692 del Código Civil nos dice en su párrafo primero: "El socio nombrado administrador en el contrato social puede ejercer todos los actos administrativos, sin embargo de la oposición de sus compañeros, a no ser que proceda de mala fe; y su poder es irrevocable sin causa legítima”).
} 
(Este último párrafo ha sido introducido por la Ley 41/2003 de 18 de noviembre, de protección de las personas con discapacidad.)

Como vemos, la extinción de los apoderamientos entre cónyuges no aparece en este precepto. En efecto, se encuentra en la regulación del matrimonio, en particular en el artículo 102 del Código Civil, cuyo párrafo primero nos dice que:

Admitida la demanda de nulidad, separación o divorcio se producen, por ministerio de la Ley, los efectos siguientes:

$1^{\circ}$ Los cónyuges podrán vivir separados y cesa la presunción de convivencia conyugal.

$2^{\circ}$ Quedan revocados los consentimientos y poderes que cualquiera de los cónyuges hubiera otorgado al otro. ${ }^{18}$

El número $1^{\circ}$ alude a una de las obligaciones de los casados: vivir juntos. Deber que el Código Civil impone en su artículo 68: "Los cónyuges están obligados a vivir juntos, guardarse fidelidad y socorrerse mutuamente." ${ }^{19}$ La presunción de convivencia se establece, a continuación, en el artículo 69: "Se presume, salvo prueba en contrario, que los cónyuges viven juntos." Se trata, por tanto, de una presunción iuris tantum, que puede destruirse demostrando que, en efecto, no conviven. ${ }^{20}$

Pero vamos a la consecuencia prevista en el número $2^{\circ}$, que es la que más me interesa ahora: el cese de la eficacia de los "consentimientos y poderes" que los cónyuges se hubiesen otorgado. ${ }^{21}$

\footnotetext{
${ }^{18}$ Toda la regulación del matrimonio en el Código Civil, recogida en el Título iv del Libro 1 (artículos 42 a 107) fue redactada por la ley 30/1981 de 7 de julio. Apenas se habían introducido modificaciones hasta la aprobación de la ley

${ }^{19}$ Éste es uno de los artículos que al contraerse el matrimonio en la forma civil debe ser leído por el autorizante (normalmente, el juez o el alcalde), así lo impone el artículo 58 del propio Código Civil.

${ }^{20}$ No hay que olvidar, de todas formas, que el cese efectivo de la convivencia de marido y mujer, según el artículo 87 del Código Civil, "es compatible con el mantenimiento o la reanudación temporal de la vida en el mismo domicilio, cuando ello obedezca en uno o en ambos cónyuges a la necesidad, al intento de reconciliación o al interés de los hijos y así sea acreditado por cualquier medio admitido en derecho en el proceso de separación o de divorcio correspondiente". No se refiere este artículo a la nulidad, pues la separación de hecho es causa de separación judicial -que no extingue el matrimonio-y de divorcio - que sí lo extingue: artículo 85 del Código Civil-; pero no de nulidad: ésta es una causa de ineficacia, la más grave, que se apoya, como sabemos, en causas coetáneas a la celebración del matrimonio.

${ }^{21}$ No terminan en el artículo 102 del Código Civil las causas de extinción del poder no recogidas en el artículo 1732. El inciso final del artículo 183 del Código Civil, que nos dice que "Inscrita en el registro central la declaración de ausencia, quedan extinguidos de derecho todos los mandatos especiales o generales otorgados por el ausente".
} 


\section{Fundamento de la norma}

Se encuentra en la base misma de la representación. Ésta, como sabemos, se apoya en la confianza ${ }^{22}$ que el poderdante o representado deposita en el apoderado o representante. ${ }^{23}$ Si nos fijamos en las causas de extinción del poder, todas se refieren a supuestos en los que, o bien se presume una pérdida de confianza (declaración de prodigalidad, concurso o insolvencia) en la persona del apoderado; o bien nos encontramos ante situaciones en las que ya no se puede saber si esa confianza todavía subsiste. Porque éste es, precisamente, el núcleo de la cuestión: la pervivencia, día tras día, momento tras momento, de la confianza depositada en el representante. De manera que si ya no podemos saber si el poderdante todavía la tiene en el apoderado (por ejemplo, por haber muerto aquél), las facultades de éste decaen.

El modo más explícito, pues no hay ni presunción de pérdida de confianza, ni imposibilidad de saber si ésta pervive, es la revocación: la declaración unilateral del poderdante manifestando su voluntad de dejar sin efecto el poder. Facultad que, con carácter general, establece el Código Civil, como vimos, en su artículo 1732, el cual se completa con el artículo 1733: "El mandante puede revocar el mandato a su voluntad y compeler al mandatario a la devolución del documento en que conste el mandato." Se trata, como vemos, de una facultad unilateral ("a su voluntad"), que no precisa, por tanto, el consentimiento del apoderado (como tampoco lo precisa, en sí mismo, el poder).

\section{Mecanismo de actuación}

El legislador presume, por tanto, que la presentación de la demanda de separación, nulidad o divorcio implica una quiebra de la confianza entre

\footnotetext{
${ }^{22}$ Por recoger la idea de manera sintética, es muy ilustrativa la explicación del romanista Álvaro d'Ors, en Derecho y sentido..., Op . cit., p. 125, al decirnos que la representación propiamente jurídica es de derecho natural, entre otras razones, "por la lealtad en que se funda, como elemento esencial, la confianza que ha de tener el representado, que delega su poder en el mandatario que le representa como delegado".

${ }^{23}$ Desde el punto de vista lingüístico aparecen aquí con claridad las dos formas del participio: el presente, que describe a un actor: poderdante -que da poder-, representado -que representa-; y el participio pasado, que alude a una actitud pasiva: apoderado - que ha recibido poder-y representado -que es sustituido por otro-. En la lengua castellana, como sabemos, el participio presente ya no es una forma verbal, sino que ha sido convertido en adjetivo (constante, prudente) o sustantivo (presidente, representante).
} 
los cónyuges. La especialidad de esta revocación, radica, pues, en que no necesita la manifestación revocatoria del poderdante. Es una presunción legal que actúa ope legis; sin necesidad, por tanto, de ser alegada por la parte a quien beneficie (el representado).

El problema radica, sin embargo, en cómo puede llegar a ser conocida esta causa de extinción del poder; pues, como hemos visto, es extraña a la voluntad del poderdante, quien incluso puede ignorar que la admisión de la demanda ha producido ese efecto.

En España, en la actualidad, disponemos de un mecanismo de notificación, entre los notarios, de las revocaciones de poderes, a través del llamado "Registro de poderes revocados", al cual acceden, como se puede deducir, las revocaciones que son autorizadas por los notarios. De manera que compareciendo un apoderado en la notaría para otorgar una escritura, el notario debe consultar el archivo y sólo autorizará el documento si el poder exhibido no ha sido revocado. Dicho archivo, no obstante, no ha eliminado el mecanismo habitual de la revocación, es decir: la comunicación, en forma fehaciente, al apoderado de que su poder ha sido revocado; y la notificación al notario autorizante del poder, si no es el mismo que autoriza la revocación, de esta última, con la finalidad de que no expida más copias auténticas del apoderamiento.

\section{Posible desactivación}

El hecho de que esta extinción actúe ipso iure no significa que no pueda desactivarse.

Una primera vía para evitar la extinción del poder, o para revivirlo, podría ser la reconciliación: ${ }^{24}$ si por la separación de los cónyuges, admitida la demanda, se presume causa de pérdida de confianza, la reconciliación, a sensu contrario, podría entenderse como motivo de recuperación de esa confianza. El punto de partida está en el artículo 106 del Código Civil, cuyo párrafo primero dice: "Los efectos y medidas previstos en este capítulo terminan, en todo caso, cuando sean sustituidos por los de la sentencia estimatoria o se ponga fin al procedimiento de otro modo." Este "otro modo", bien podría ser un de-

\footnotetext{
${ }^{24}$ Aparte de las normas sanatorias, por vía de reconciliación, que se mencionan en el texto, hay alguna otra en nuestro Código Civil. El artículo 757 nos dice que: "Las causas de indignidad dejan de surtir efecto si el testador las conocía al tiempo de hacer testamento o si, habiéndolas sabido después, las remitiere en documento público"; el artículo 856 señala: "La reconciliación posterior del ofensor y del ofendido priva a éste del derecho de desheredar y deja sin efecto la desheredación ya hecha”.
} 
sistimiento, que retrotraería la situación jurídica al inicio del procedimiento. El desistimiento sería, de hecho, la forma procesal de la reconciliación, a la cual se refiere el Código en el artículo 84, párrafo primero, al decirnos que: "La reconciliación pone término al procedimiento de separación y deja sin efecto ulterior lo en él resuelto; pero los cónyuges deberán poner aquélla en conocimiento del juez que entienda o haya entendido del litigio."

En términos análogos, para el divorcio, ${ }^{25}$ se pronuncia el artículo 88 en su primer párrafo: "La acción de divorcio se extingue por la muerte de cualquiera de los cónyuges y por su reconciliación, que deberá ser expresa cuando se produzca después de interpuesta la demanda." ${ }^{26}$

Las consecuencias de la reconciliación afloran también en el ámbito sucesorio: el artículo 835 del Código, encuadrado en la regulación de la legitima del cónyuge supérstite (que en el derecho común tiene forma de usufructo), es muy claro en su párrafo segundo: "Si entre los cónyuges separados hubiese mediado perdón o reconciliación, el sobreviviente conservará sus derechos."

Todo lo expuesto nos puede inducir a pensar que el poder extinguido ex artículo 102 del Código Civil revive como consecuencia de la reconciliación. No es así. Las facultades anulatorias de la reconciliación no son omnímodas. En particular, y esto es lo que más nos interesa en este momento, no alcanzan a reactivar el apoderamiento. En efecto, el artículo 106 del Código cierra la puerta a una posible resurrección del poder extinguido, pues su segundo párrafo señala: "La revocación de consentimientos y poderes se entiende definitiva." 27

Busquemos, pues, otra solución: cabe la posibilidad de dejar sin vigor esa revocación, mediante la concesión de un nuevo poder, que, por fuerza, ya sería posterior a la admisión de la demanda presentada en alguna de las causas de crisis matrimonial. Nos encontraríamos, por tanto, ante un poder diferente del anterior.

${ }^{25}$ La reconciliación se refiere sólo a la separación y al divorcio, no a la nulidad, la cual es una forma de ineficacia en la que está involucrado el interés público (recordemos que el artículo 74 del Código atribuye al Ministerio Fiscal legitimación activa); y, por tanto, no está en manos de los particulares -los contrayentes- dar marcha atrás en el procedimiento apoyándose en un motivo, la reconciliación, que nada tiene que ver con las causas que provocan la nulidad.

${ }^{26}$ El párrafo segundo de este artículo 88 recoge una norma que, aunque superflua, es muy aclaratoria: "La reconciliación posterior al divorcio no produce efectos legales, si bien los divorciados podrán contraer entre sí nuevo matrimonio.” Es decir, se permite la reincidencia.

${ }^{27}$ No es el único efecto que se mantiene y que, por tanto, no es alcanzado por la reconciliación: el artículo 1443, relativo al régimen económico matrimonial de separación, nos dice: "La separación de bienes decretada no se alterará por la reconciliación de los cónyuges en caso de separación personal..." 
Distinto sería, sin embargo, el caso de un poder con cláusula de subsistencia; es decir, dado con anterioridad a la admisión de la demanda, pero con la previsión, en el mismo poder, de que perviva en el caso de crisis matrimonial. No es clara, a priori, la solución que debería darse a este supuesto.

A favor de mantener la extinción del poder pese a esa cláusula de subsistencia están los términos taxativos del artículo 102 ("se producen por ministerio de la ley los efectos siguientes...”).

Sin embargo, hay sólidos argumentos a favor de sostener esta posibilidad. En primer lugar, porque el apoderamiento, que opera casi siempre en el ámbito patrimonial, no está sustraído del principio de la autonomía de la voluntad. ${ }^{28}$ No parece que haya razones de peso que impidan a una persona otorgar un poder a su cónyuge aún en el caso de que sobrevenga una crisis matrimonial. No encuentro contradicción ni con las leyes, ni con la moral, ni con el orden público. Es una materia que queda circunscrita al interés del poderdante; de manera que si ese es su interés, no creo que haya óbice para permitírselo. Es muy dueño de arriesgarse de ese modo.

Tras la Ley 41/2003 hay un argumento adicional: si se permite la subsistencia del poder, por voluntad del poderdante en el momento de su otorgamiento, en los casos de incapacidad o incapacitación, con más motivo en los supuestos de crisis matrimonial. Pues en los supuestos del artículo 1732 in fine el representado ya no puede volver a expresar su voluntad de manera adecuada (salvo, claro, que recupere la capacidad): queda atrapado por su poder, que sobrevive a su incapacidad. Es prisionero de la declaración de voluntad hecha cuando gozaba de capacidad. Sin embargo, el poderdante del poder que supere las crisis matrimoniales conserva -en principio- su capacidad; y, por tanto, está en condiciones de revocar ese poder cuando quiera.

Volver al Índice >>

${ }^{28}$ Este principio no es sino una manifestación - muy señalada, eso sí- de la libertad como valor superior (artículo 1 de la Constitución española). En el Código Civil el precepto más explícito, aunque no el único, es el artículo 1255: "Los contratantes pueden establecer los pactos, cláusulas y condiciones que tengan por conveniente siempre que no sean contrarios a las leyes, a la moral y al orden público.” 